2004s-59

\title{
Snow Removal Auctions in Montreal: Costs, Informational Rents, and Procurement Management
}

\author{
Véronique Flambard, Pierre Lasserre,
} Pierre Mohnen

\begin{tabular}{c}
\hline Série Scientifique \\
Scientific Series
\end{tabular}

Montréal

Décembre 2004

(C) 2004 Véronique Flambard, Pierre Lasserre, Pierre Mohnen. All rights reserved. Reproduction partielle permise avec citation du document source, incluant la notice $\mathbb{C}$.

Short sections may be quoted without explicit permission, if full credit, including $\mathbb{C}$ notice, is given to the source.
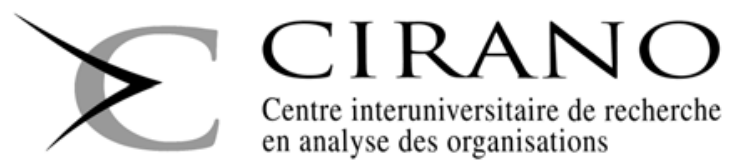

Centre interuniversitaire de recherche en analyse des organisations 


\section{CIRANO}

Le CIRANO est un organisme sans but lucratif constitué en vertu de la Loi des compagnies du Québec. Le financement de son infrastructure et de ses activités de recherche provient des cotisations de ses organisations-membres, d'une subvention d'infrastructure du Ministère du Développement économique et régional et de la Recherche, de même que des subventions et mandats obtenus par ses équipes de recherche.

CIRANO is a private non-profit organization incorporated under the Québec Companies Act. Its infrastructure and research activities are funded through fees paid by member organizations, an infrastructure grant from the Ministère du Développement économique et régional et de la Recherche, and grants and research mandates obtained by its research teams.

PARTENAIRE MAJEUR

$$
\text { Les organisations-partenaires / The Partner Organizations }
$$

. Ministère du Développement économique et régional et de la Recherche [MDERR]

PARTENAIRES

. Alcan inc.

. Axa Canada

. Banque du Canada

. Banque Laurentienne du Canada

. Banque Nationale du Canada

. Banque Royale du Canada

. Bell Canada

. BMO Groupe Financier

. Bombardier

. Bourse de Montréal

. Caisse de dépôt et placement du Québec

. Développement des ressources humaines Canada [DRHC]

. Fédération des caisses Desjardins du Québec

. GazMétro

. Groupe financier Norshield

. Hydro-Québec

. Industrie Canada

. Ministère des Finances du Québec

. Pratt \& Whitney Canada Inc.

. Raymond Chabot Grant Thornton

. Ville de Montréal

. École Polytechnique de Montréal

. HEC Montréal

. Université Concordia

. Université de Montréal

. Université du Québec

. Université du Québec à Montréal

. Université Laval

. Université McGill

. Université de Sherbrooke

ASSOCIE A :

. Institut de Finance Mathématique de Montréal (IFM²)

. Laboratoires universitaires Bell Canada

. Réseau de calcul et de modélisation mathématique $\left[\mathrm{RCM}^{2}\right]$

. Réseau de centres d'excellence MITACS (Les mathématiques des technologies de l'information et des systèmes complexes)

Les cahiers de la série scientifique $(\mathrm{CS})$ visent à rendre accessibles des résultats de recherche effectuée au CIRANO afin de susciter échanges et commentaires. Ces cahiers sont écrits dans le style des publications scientifiques. Les idées et les opinions émises sont sous l'unique responsabilité des auteurs et ne représentent pas nécessairement les positions du CIRANO ou de ses partenaires.

This paper presents research carried out at CIRANO and aims at encouraging discussion and comment. The observations and viewpoints expressed are the sole responsibility of the authors. They do not necessarily represent positions of CIRANO or its partners. 


\title{
Snow Removal Auctions in Montreal: Costs, Informational Rents, and Procurement Management
}

\author{
Véronique Flambard ${ }^{*}$, Pierre Lasserre ${ }^{\dagger}$, Pierre Mohnen ${ }^{*}$
}

\begin{abstract}
Résumé / Abstract
Par des méthodes non paramétriques adaptées de Guerre et al. [2000], nous évaluons la distribution des coûts et les rentes informationnelles correspondant à 666 contrats de déneigement mis aux enchères par la Ville de Montréal. Les résultats sont conformes à la théorie des enchères concurrentielles : corrélation positive entre soumissions et coûts; rentes croissantes avec la variance des coûts et décroissantes avec le nombre d'enchérisseurs. Tant les soumissions que les coûts diminuent au cours de la période, tandis que les rentes sont stables. Ces résultats sont à mettre au crédit de la Ville : elle a su exploiter les économies d'échelle sans réduire la concurrence, et susciter un progrès technologique plus élevé que la moyenne nationale grâce au découpage des territoires.
\end{abstract}

Mots clés : enchères d'approvisionnement, estimation non paramétrique, rentes d'information, conception des tâches, contrats municipaux.

Using nonparametric estimation techniques adapted from Guerre et al. [2000], we infer cost distributions and informational rents, from 666 snow removal contracts offered for tender by the City of Montreal. Our results are compatible with standard received theory of competitive auctions: there is a positive correlation between costs and bids; rents increase with the variance of costs and decrease with the number of bidders. Bids and costs have decreased over the sample period, while informational rents remained stable. The City deserves credit for these results. It has succeeded in exploiting economies of scale while maintaining competition; and it was instrumental in promoting above Canadian average technological progress by its design of snow-removal territories.

Keywords: procurement auction, nonparametric estimation, informational rents, task design, municipal contracts.

Codes JEL : D44, H400

\footnotetext{
* Please address all correspondence to Véronique Flambard, Department of Economics, Grant MacEwan College, City Centre Campus, 6-329 10700-104 Avenue, Edmonton, Alberta, Canada, T5J 4S2, Tel. (780) 497-4794, Fax (780) 497-5308, email: flambardv@macewan.ca.

'Université du Québec à Montréal and CIRANO.

\$ Maastricht University and CIRANO.
} 


\section{Introduction}

Snow removal is an important activity for the City of Montreal. Approximately 2,000 kilometers of streets and 3,500 kilometers of sidewalks are cleared after each snowstorm. Every year, on average $7,500,000$ cubic meters of snow are removed and carried to snow dumps. The budget for snow removal was $\$ 52$ million in 1998, accounting for about 3\% of the total budget of the City. Considering the high cost of snow removal, the City wants to make sure that it buys outside services at minimum cost; it needs to know fairly accurately the contractors' actual costs. One way to get this information is for the City to carry out some of the work itself, as it does, while contracting out the rest to private suppliers. This kind of benchmarking has its limits, however, because a municipality is often less efficient than the private sector in providing public services.

It is well known that, under conditions which include symmetry among bidders and the absence of collusive behavior among suppliers, appropriate auctions insure that the most efficient supplier is selected and that the rent left in the hands of that supplier by the auctioneer is minimized, given the number of bidders. One may wonder then, why it is desirable to know more about contractors' costs.

One important reason is that the definition of the service to be contracted out may substantially affect its cost. For instance, the mapping and the size of the territories specified in the contracts affect the scale of snow-clearing and the distance to the snow dumping site. Knowledge of such repercussions may help the municipality streamline its snow removal and transportation operations.

A second important reason is that the size of the territories may trigger innovations. Contractors are given time limits to clear school and hospital areas after a snowstorm, therefore the larger the territories the more efficient the machinery has to be.

Finally, a third important reason to seek knowledge of contractors' costs and rents is that rationalization of the work being auctioned out may have an impact on competition in the auctioning process. The City may for instance redefine its territory subdivisions in such a way as to reap economies of scale and induce technological progress. An extreme case would be to have one single territory and delegate the activity to a single supplier. Such a practice, however, is likely to affect market structure. When comes the time to renew the contract (say every five years), fewer firms would be big enough to 
participate, but there would also be fewer territories to compete for. Therefore the level of competition, and the rent that the winning firm could reap from the contract, would be affected ${ }^{1}$. This suggests a potential trade-off between competition and economies of scale.

We propose to infer the contractors' costs, and the rents they obtain, using an econometric model of auction bidding applied to data on private bids for snow removal contracts auctioned off by the City of Montreal on 61 procurements between 1990 and 1998. Existing theoretical results on bidding strategies, bidding rents and optimal procurement rely on the unknown distribution of private values (private costs in the present context). Empirical work is therefore needed to evaluate the performance of such a procurement mechanism and to provide insights into ways to improve upon it. Our work is a contribution in this direction. From a theoretical model, adapted from Riley and Samuelson [1981], we derive a structural econometric model from which the contractors' costs, cost distribution and rents can be computed.

The estimation raises several econometric issues, which have been examined by Paarsch [1992], Donald and Paarsch [1993, 1996], Florens, Hugo and Richard [1997], Krasnokutskaya [2002], JofreBonet and Pesendorfer [2003] and Flambard and Perrigne [2004] in the context of procurements and by Laffont and Vuong [1993], Elyakime, Laffont, Loisel and Vuong [1994], Laffont, Ossard and Vuong [1995], Guerre, Perrigne and Vuong [2000] and Li, Perrigne and Vuong [2002], in the context of sale auctions. We adapt the Guerre, Perrigne and Vuong [2000] procedure to a procurement mechanism. This method has the advantage of being fully nonparametric, so that it does not impose any functional form on the unknown distributions. However, to avoid the curse of dimensionality in high dimensions with nonparametric estimation, we introduce a variable reduction technique to model the heterogeneity of the auctioned contracts instead of keeping to the main explanatory variable for characterizing the contracts as is usually done. Researchers have developed methods which reduce the dimensionality in regression methods and have allowed for partly parametric modeling. The resulting models can be grouped together as so-called semiparametric models. Relying on this literature (see Horowitz[1998])

\footnotetext{
${ }^{1}$ We do not discuss here the possibility of regulating a sole supplier (a monopoly) on the basis of its cost, without re-auctioning the contract regularly, because municipal law requires that any services, above a given expenditure, be put up for auction.
} 
we have chosen to use a single index model. The latter offers the advantage to fully exploit the relation between the dependent variable (the bids for us) and the independent variables (the characteristics of the contracts here) instead of merely exploiting the correlation within the vector of independent variables like with other methods. Since we are interested in studying the relationship between the service to be performed (and in particular the mapping and the size of the territories) and the resulting bids, we found the semiparametric modeling for the regression of the bids conditionally on the contract characteristics particularly interesting.

The paper is or ganized as follows. Section 2 describes the institutional features and our assumptions for the present study. A game-theoretic model of procurement auctions, where firms compete on price, is developed in section 3. Section 4 is devoted to the identification of the structural elements and to the description of the estimation procedure. The results of the estimations are reported and analyzed in section 5. Finally, we summarize and conclude the paper in section 6 .

\section{A Description of the Auctioning of Snow Removal Contracts in Montreal}

Every year, the City of Montreal publishes an invitation to tender for several snow removal contracts, corresponding to different territories of the City. The contracts are standardized and differ only with respect to the characteristics of the territories. Firms interested in submitting bids request specifications from the City. For each contract, the City provides a map, a description of the territory (length and distance to the snow dump) as well as (after 1990) the reserve price. On the day of the auction, the sealed bids are opened and the identity of all bidders and their bids are announced to those present. The contracts under auction have five year terms and put the winner in charge of cleaning up snow from the streets and sidewalks between November 15 and March 15 ("the snow season") during these five years, at the agreed price.

Participants bid on the price, in dollars per meter of street length per year, based on a "normal" snowfall of 200 centimeters per year. The lowest bid is accepted for each contract provided that the 
specified qualifications are met: the candidate must have the required equipment and must provide adequate financial warranties. In the course of contract execution, the price may be adjusted to allow for abnormal snowfalls. The price paid to the firm is increased by $0.4 \%$ for each centimeter above 200 centimeters; similarly, the price is reduced by $0.4 \%$ for each centimeter of snowfall below 200 centimeters down to 100 centimeters. Consequently, for a winning bid $p_{i l}$ by firm $i$ in contract auction $l$, the yearly amount $a_{i l}$ received in dollar per meter of street length, is ${ }^{2}$ :

$$
a_{i l}=.6 p_{i l} I_{\{q \leq 100\}}+[1+.004(q-200)] p_{i l} \mathbb{I l}(q>100)
$$

where $q$ is the actual snowfall during the year under consideration. As a result, the supplier is certain to receive at least $60 \%$ of the revenues corresponding to a normal snowfall of 200 centimeters at the bidded price, but shares with the City the risk associated with yearly fluctuations above 100 centimeters.

Total revenue to the firm is the product of total street length in the territory (in meters) by yearly amount $a_{i l}$. Although prices are quoted in the same units from one contract to the other, each bid can be different, not only because auctions on different territories are independent, but also because territories have different characteristics that affect the cost per meter. The City of Montreal requires a list of pieces of equipment for each territory. The supplier has to prove that he has the required capital. If he does not have all of it before the auction, he has to commit himself to buy the other pieces before the beginning of the contract.

We have data on the winning and losing bids, together with contract specifications, for 61 procurements of snow removal tendered between 1990 and 1998 by the City of Montreal, for a total of 457 bids. The number of bidders varies across auctions from two to fourteen.

Table 1 gives an overview of the main trends. Winning bids for snow removal contracts with the City of Montreal have gone down by $22 \%$ between 1990 and 1998 . One possible explanation for this decline, as we will see in section five, is the returns to scale associated with the increase in territory size and technological progress. Since the contracts have five year terms, the policy of increasing territory

\footnotetext{
${ }^{2}$ Usually it snows well over 100 centimeters a year (the average over the last 20 years was 206.6 centimeters). For the last five years the precipitations were between 179 and 327 centimeters. The lowest level of snowfall ever was 87.5 centimeters in the winter of 1979-1980 while the lowest level in our dataset was 131 centimeters.
} 
size could only be introduced progressively. On a given year, any new territory division can apply only to territories under renewal and can be offered only to the cohort of contractors whose current contracts are expiring. Transition technicalities and other historical features account for the fact that, over our 1990-98 sample period, one-quarter of the contracts are up for renewal each year for four years while, the fifth year, no procurement auction is organized (1994). This illustrates some of the constraints applying to changes in territory size shown in Table 1.

Another explanation for the decline in bids might be increased competition. If the pool of potential suppliers in the Montreal area remains constant as territory size increases and the number of territories diminishes, then the number of participants in Montreal has to increase at each auction. However, changes in territory size may induce some suppliers to seek other work. We shall examine which of the two explanations is most likely to prevail.

In Table 1, we also present the chronological evolution of the number of contracts, the number of bids and the resulting average number of bids per contract. We notice a reduction of 3 contracts in 1991 for the cohort of contracts awarded in $1986^{3}$ and renewed in 1991 and a reduction of 2 contracts in 1993 for the cohort of contracts awarded in 1988 and renewed in 1993.

There is no systematic pattern in the number of actual bidders for each successive contract within a given cohort. It dropped sharply in 1996. It shooted up from 6.67 in 1992 to 10.83 in 1997 . It remained at the same level between 1993 and 1998, and it increased in 1995 compared to 1990 . In Table 3, we present some descriptive statistics for the sample period (1990-1998).

\section{The Procurement Auction Model}

We shall set up a model of procurement auctions based on assumptions which we consider to be realistic in the institutional context under study. The observed data on bids and winning bids are supposed to be generated by this model. Together with the characteristics of the contracts they will allow us to infer the contractors' private costs and informational rents. The model will also help us assess the effects

\footnotetext{
${ }^{3}$ Even though we have data on snow removal auction after 1986 , we estimate the firms' rents and costs using only the auctions with a reserve price (which was introduced in 1990) over the period 1990-1998.
} 
on costs and rents of increases in territory size and other management decisions. We first turn to the assumptions underlying our model.

\subsection{Institutional Details and Model Assumptions}

Reserve Price. In 1990, a public reserve price $p_{0 l}$ for contract $l$ was introduced. We observe no drop in the number of bidders after 1990 compared to the period before 1990 . The mean number of participants, during the period without a maximum price, was 7.54 with a maximum of ten, whereas, during the period with a reserve price, the mean was 8.26 , with a maximum of fourteen participants. However, many bids are close to the reserve price. To evaluate the proportion of bids that could be truncated because of that, we have estimated nonparametrically the probability to draw a bid within plus or minus five percent of the reserve price for an average tract. We found that it is quite high and equal to 0.19. Therefore we will assume that the reserve price is binding in our period of study.

Knowledge structure. We assume that the set of potential bidders is common knowledge and that it is constant and equal to $I^{4}$. Firm $i$ knows its own cost but only the distribution of the cost of its competitors. Agents' private costs are assumed to be independently drawn from a common distribution on $\left[\underline{c_{l}}, \overline{c_{l}}\right]$ with density function $f_{l}(\cdot)$. This stochastic structure is common knowledge. It is likely that individual costs differ across bidders because of differences in capital stock (number, age and type of machines), expertise, preferences for a territory (firms specialize in different types of territories or may have affinities with the municipal team), capacity utilization (which depends on the other commitments of the firm) and location (a firm must rent a parking space if the territory is too far away). We assume that the bidders know from personal experience and from visiting the auctioned territory how much it would cost them to realize a particular contract. To the extent that individual cost differences are more important than uncertainties about the task which affect all firms symmetrically, the bidding process is best modeled as an independent private-values (IPV) procurement auction.

Risk, symmetry, independence. Because firms typically obtain numerous contracts from several

\footnotetext{
${ }^{4}$ The reserve price is binding and therefore the number of actual bidders $I_{l}^{*}$ varies with the reserve price. However, the number of potential bidders $I$ is independent of the reserve price.
} 
municipalities, carry out other activities or can rent their equipment ${ }^{5}$, we may assume them to be risk neutral at the level of a single auction. Discrimination, e.g. in favor of Montreal suppliers, in the award of procurement contracts, is prohibited; we assume that all bidders are otherwise indistinguishable, so that each firm is treated alike. More specifically, we assume that we don't have groups of firms with systematic cost differences (say low cost firms and high cost firms) with respect to their size, location ${ }^{6}$, capacity of production ${ }^{7}$ or work experience for example.

A firm's cost for performing a given task may change over time because of new capital acquisition, new experience, differences in auctioned territories or differences in alternative opportunities. Costs are assumed to be independently distributed over time. Moreover, we assume that the shape of the distribution does not change over time, only the interval over which it is defined. Consequently, the auctions are treated as a succession of independently repeated games.

We may also reasonably consider that the bids are independent across auctions in a given year. Indeed, although a firm may bid on several contracts, it cannot do so with prior knowledge of any auction outcome; thus it cannot bid conditionally on the results of other auctions. The maximum number of contracts it can win depends on its capital stock and on the number of financial warranties it must provide with its bids. ${ }^{8}$ If a contractor bids on, and wins, more contracts than he can ultimately deliver, the City decides which ones he will eventually retain given his capacity. Since such ex post assignment is done in such a way as to minimize the City's cost rather than to maximize the bidder's rent, the latter is not likely to win by using, in a specific auction, any strategy involving other auctions. Also, a firm is not able to benefit from economies of scale or scope from contracts with neighboring

\footnotetext{
${ }^{5}$ Some firms buy extra equipment on purpose, usually when these machines can be used in the out-of-snow season, to rent them to townships because of the very good return associated with this practice.

${ }^{6}$ The location may create asymmetry on western tracts but not on eastern tracts (see Flambard and Perrigne [2004]). As a matter of fact, Flambard and Perrigne find slight differences in rents and cost densities between the firms close to and far away from the western tracts. However, when performing a Smirnov-Kolmogorov test, they find a weak rejection of stochastic dominance on western tracts (and a strong rejection on eastern tract). Therefore, in the absence of asymmetry on eastern tracts and in the absence of definite evidence of asymmetry on western tracts, we assume that the bidders can be treated in the same manner. Moreover, the estimations would be less robust given our relatively small sample sizes if we estimated the densities of bids separately for each group of bidders $G_{j}\left(b_{i l}\right) \forall j=1,2$ and this lack of robustness would outweigh the potential benefit of considering different groups of bidders.

${ }^{7}$ The capacity of production cannot be measured by counting only the snow removal contracts with the City of Montreal. Other commitments such as rental contracts and snow removal contracts with other municipalities or customers would also need to be considered but we don "t have this information. Moreover, firms indicate the maximum number of contracts they wish to win. Therefore, firms can't win more contracts than they are able to undertake.

${ }^{8}$ Each bid must be accompanied by a deposit and by a warranty issued by a Canadian insurance company of an amount corresponding to $60 \%$ of the value of the contract.
} 
territories: removing snow on one territory cannot reduce the cost on neighboring territory because the terms of the contract require that a firm which has two (or more) contracts must get all the required equipment simultaneously on each of the territories it is responsible for. Therefore, there is no gain, and no risk, from bidding at several auctions.

Finally, the City of Montreal is not the only town which solicits bids for snow removal, and snow removal is not the sole activity of the firms involved. Over the year there are numerous invitations for tender, firms often bid simultaneously with several towns for many contracts, and they enter other types of contracts with other customers. Globally, firms win the number of contracts they wish (with one or several municipalities). Consequently, we shall consider that the procurement auctions for snow removal are individually independent auctions.

Competition. The demand for snow removal is relatively price insensitive, as public opinion is in favor of clearing the streets. For instance, initiatives by the City of Montreal to reduce overtime expenditures by suspending snow removal on weekends has raised public criticism. However, as is plain from the above discussion on independence, there are many buyers, many suppliers, many products, and the rules do not facilitate the control of any market or auction procedure.

Prohibiting bidders from using the same equipment on neighbouring territories, as does the City of Montreal, limits the benefit of a collusion for territory assignments. Barriers to entry are low: firms who handle snow removal also carry out other activities, like landscaping, general construction or excavation. Their equipment can have many uses, especially their trucks which can be equipped with removable plows. As a matter of fact, we have identified 52 different firms bidding for snow removal in Montreal between 1990 and 1998, some of them entering and others leaving the market. Obviously, differences among firms, the sheer number of potential entrants, and heterogeneity in the territories would complicate cartel coordination. For all these reasons, the bidding behavior is modeled as a noncooperative game under incomplete information. 


\subsection{Bidding Strategies}

We begin our presentation of the model with an informal discussion of the bidding game. We then determine its outcome and interpret it.

Consider a "buyer" (the City in our case) who auctions, in a first-price sealed-bid auction, several fixed-price contracts to $I$ potential firms $(I \geq 2)$. Although the contracts are relatively homogeneous, they are not identical. Therefore for each contract $l$, we allow the distribution of costs to depend on the characteristics of the contract $z_{l}$ (to be defined in the next section). Let us denote the cumulative distribution function $F_{l} \equiv F\left(\cdot \mid z_{l}, \cdot \leq p_{o l}\right)$, the corresponding density function $f_{l} \equiv f\left(\cdot \mid z_{l}, \cdot \leq p_{o l}\right)$, the survival function $S_{l}=1-F_{l}(\cdot) \equiv S\left(\cdot \mid z_{l}, \cdot \leq p_{o l}\right)$, and the interval over which the cost distribution is defined as $\left[\underline{c_{l}}, \overline{p_{o l}}\right] \equiv\left[\underline{c}\left(z_{l}\right), \bar{p}_{o l}\left(z_{l}\right)\right]$.

Total revenue and total cost depend on the actual snowfall, $q$. Total cost increases with the level of snow removal as firms have to operate their equipment and pay their employees for each extra hour worked. According to the snow-removers that we have interviewed, the costs increase linearly with the level of snowfall; thus we assume that the cost per centimeter of snowfall is constant. Snow removers also bear a fixed cost, which may differ from one territory to another, if only because equipment requirements differ between territories. Thus we write the total cost for firm $i$ in contract $l$ as $k_{i l}+\frac{v_{i l}}{200} q$ where $k_{i l}$ is the fixed cost and $v_{i l}$ is the variable cost corresponding to a snowfall of 200 centimeters. We also define $c_{i l}=k_{i l}+v_{i l}$ as the total cost corresponding to a snowfall of 200 centimeters. If we assume that $E(q)=200$, the expected profit, conditional on winning the contract, can be rewritten as ${ }^{9}$ :

\footnotetext{
${ }^{9}$ The derivations follow. Given the per meter revenue defined by (1), the expected profit for the winner $i$ of auction $l$ is:

$$
\begin{aligned}
\phi_{i l} & =\int_{0}^{100}\left[.6 p_{i l}-k_{i l}-\frac{v_{i l}}{200} * q\right] \gamma(q) d q \\
& +\int_{100}^{\infty}\left[(1+.004(q-200)) p_{i l}-k_{i l}-\frac{v_{i l}}{200} * q\right] \gamma(q) d q
\end{aligned}
$$

where the expectation is taken over snowfall, whose density is $\gamma(q)$. If we assume that $E(q)=200$, the expected profit, conditional on winning the contract, can be rewritten as: $\phi_{i l}=A p_{i l}-c_{i l}$ where $A$ is defined as:

$$
A=\left[.6 \int_{0}^{100} \gamma(q) d q+\int_{100}^{\infty}(1+.004(q-200)) \gamma(q) d q\right]
$$

Because observing less than 100 centimeters of snowfall a year is a rare event, we can assume that $\int_{0}^{100} \gamma(q) d q=\operatorname{Pr}(q \leq$ $100) \sim 0$. We decided to make this assumption rather than estimate the density $\gamma(q)$ because the error due to the omission of climate change in the estimation might have outweighed the gain obtained from a more precise specification of snow conditions. It follows that $A \sim 1$ and then that $\phi_{i l} \sim p_{i l}-c_{i l}$.
} 
$\phi_{i l} \sim p_{i l}-c_{i l}$. According to whether it gets the contract or not, the profit of firm $i$ bidding for contract $l$ is thus equal to:

$$
\pi_{i l}=\left[p_{i l}-c_{i l}\right] * \mathbb{I}\left(p_{i l}<p_{j l}, j \neq i \mid p_{i l} \leq p_{o l}\right)
$$

Assuming that any two bidders with the same cost would submit the same bid, we restrict the analysis to equilibria in which all firms have the same strictly increasing and differentiable strategy $b_{l}(x)$. Although bidders have the same equilibrium strategy function, they differ by the argument $x$ at which the function is evaluated. Riley and Samuelson [1981] have solved the Bayesian Nash equilibrium of such a game in the context of a sale auction. Let us compute the Bayesian Nash equilibrium of this game. Bidder $i$ with bidding price $b_{l}(x)$ wins if and only if all his rivals have a cost above $b_{l}^{-1}\left(b_{l}(x)\right)=x$. In equilibrium, each player $i$ would want to choose the strategy $b_{l}(x)$ that maximizes his expected payoff ${ }^{10}$ :

$$
E \pi\left(c_{i l}, x\right)=\left[b_{l}(x)-c_{i l}\right] * S_{l}^{I-1}(x)
$$

The first-order condition for maximization is:

$$
\frac{d}{d x}\left[b_{l}(x) S_{l}^{I_{l}-1}(x)\right]=c_{i l} \frac{d}{d x}\left[S_{l}^{I-1}(x)\right]
$$

By requiring the observations to correspond to a Nash equilibrium, we must have $x=c_{i l}$, hence

$$
\frac{d}{d c_{i l}}\left[b_{l}\left(c_{i l}\right) S_{l}^{I-1}\left(c_{i l}\right)\right]=c_{i l} \frac{d}{d c_{i l}}\left[S_{l}^{I-1}\left(c_{i l}\right)\right]
$$

Solving the differential equation (2) under the boundary condition ${ }^{11} b_{l}\left(p_{o l}\right)=p_{o l}$, an optimally chosen

${ }^{10}$ We first define the probability of winning when bidding the amount $b_{l}(x)$ as:

$$
\begin{aligned}
\operatorname{Pr}(i \text { wins } l) & =\operatorname{Pr}\left(b_{l}(x)<b_{l}\left(c_{j l}\right), \forall j \neq i \mid z_{l}, x \leq p_{o l}\right) \\
& =\operatorname{Pr}\left(x<c_{j l}, \forall j \neq i \mid z_{l}, x \leq p_{o l}\right) \\
& =S_{l}^{I-1}(x)
\end{aligned}
$$

where $I$ is the number of potential players for contract $l$. This result holds because of the independence of costs and because of the monotonicity of $b_{l}(\cdot)$.

${ }^{11} \mathrm{As}$ a matter of fact, condition (2) is just one of the conditions necessary for equilibrium. Another necessary condition is that $b_{l}\left(p_{0 l}\right)-p_{0 l}$ be nonnegative. Otherwise, a bidder endowed with a cost $p_{0 l}$ could do better by not participating in the auction. It is also necessary that $b_{l}\left(p_{0 l}\right)-p_{0 l}$ be non-positive. Otherwise, when $c_{i l}=p_{0 l}$ a small decrease in the bid from the common strategy $b_{l}\left(p_{0 l}\right)$ to $b_{l}\left(p_{0 l}\right)-\varepsilon$, such that $b_{l}\left(p_{0 l}\right)-p_{0 l}-\varepsilon>\mathbf{0}$, would raise bidder i's expected payoff from zero (since $\left.S_{l}^{I-1}\left(p_{0 l}\right)=\mathbf{0}\right)$ to some small positive number (because $\left.S_{l}^{I-1}\left(b_{l}^{-1}\left(b_{l}\left(p_{0 l}\right)-\varepsilon\right)\right) \neq \mathbf{0}\right)$, and consequently $b_{l}(\cdot)$ 
bid $b_{l}\left(c_{i l}\right)$ must satisfy:

$$
b_{l}\left(c_{i l}\right)=c_{i l}+\frac{\int_{c_{i l}}^{p_{0 l}} S_{l}^{I-1}(c) d c}{S_{l}^{I-1}\left(c_{i l}\right)}, i=1, \ldots, n
$$

The second-order condition is satisfied because $b_{l}(\cdot)$ is assumed to be strictly increasing ${ }^{12}$. Note that this decision rule satisfies the original assumption of an increasing bid function: the lower a contractor's cost, the lower his bid.

The winning bidder is the contractor with the lowest cost $c_{l(1)}$. In choosing his bid, each agent assumes he has the lowest cost. We can show that $b_{l}\left(c_{i l}\right)$ as defined in $(3)$ is equal to the expected second-lowest cost $c_{l(2)}$ conditional on the bidder's information that his own cost is $c_{l(1)}$. The bidder estimates how far on average the next cost is above his own cost. He then submits a bid that exceeds his own cost by precisely that amount. Hence, on average, the price reached in a first-price sealedbid procurement auction is the second lowest cost. The second term in (3) can be interpreted as the informational rent that accrues to the winning bidder. The more potential bidders there are, the lower is the informational rent and hence the cost to the municipality. Furthermore, the larger the variance, the larger the difference between the lowest cost and the second lowest cost. The economic rent to the winning bidder tends to increase with the variance of the distribution as shown in McAfee and McMillan $[1986,1987]$.

\section{Identification and Estimation of the Structural Model}

In this section, we explain how we estimate the theoretical model of section 3 , using the method developed for a sale auction by Guerre, Perrigne and Vuong [2000]. The basic idea underlying the structural estimation is the following. Because bids are related to private costs, which are random and distributed as $F_{l}(\cdot)=F\left(\cdot \mid z_{l}, \cdot \leq p_{o l}\right)$, by equation $(3)$ bids are also random and have a distribution $G_{l}(\cdot)=G\left(\cdot \mid z_{l}\right)$. We denote the distribution of the observed bids (the distribution that can be directly estimated from the bids and is truncated by the reserve price) $G_{l}^{*}(\cdot)=G^{*}\left(\cdot \mid z_{l}, \cdot \leq p_{o l}\right)$. Our strategy

would not be the best strategy. These last two restrictions determine the boundary condition $b_{l}\left(p_{0 l}\right)=p_{0 l}$ which implies that the least efficient participating firm earns zero rent. This condition is not very restrictive insofar as the interval $\left[\underline{c}_{l}, p_{0 l}\right]$ is common knowledge.

${ }^{12}$ The proof is available upon request. 
is to estimate $G_{l}^{*}(\cdot)$ nonparametrically and to retrieve $F_{l}(\cdot)$. We can then construct a pseudo-sample of bidders' costs, knowing the bid distribution and the observed bids, derive the cost distribution, and compute the informational rents enjoyed by the winning bidders.

The model is identified if the structural elements of the model, the latent cost distribution $F_{l}(\cdot)$ and the potential number of bidders $I$ can be recovered from observations, which are the bids and the number of actual bidders $I_{l}^{*}$. The first theorem in Guerre, Perrigne and Vuong [2000] provides a solution to the identification problem. We adapt their result to the context of a procurement auction.

The result relies upon the fact that the strategy derivative $b_{l}^{\prime}(\cdot)$, the cost distribution $F_{l}(\cdot)$ and the cost density $f_{l}(\cdot)$ can be eliminated simultaneously from the first-order-condition by introducing the bid distribution $G_{l}(\cdot)$ and the bid density $g_{l}(\cdot)$ as follows.

Rewrite the first-order condition (2) so as to obtain:

$$
\frac{b^{\prime}\left(c_{i l}\right)}{f_{l}\left(c_{i l}\right)} \frac{1-F_{l}\left(c_{i l}\right)}{\left(I_{l}-1\right)}=b_{l}\left(c_{i l}\right)-c_{i l} .
$$

The distribution of the observed bids $G_{l}^{*}(\cdot)$ is:

$$
\begin{aligned}
G_{l}^{*}(p) & =\operatorname{Pr}\left(b_{l}(c) \leq p \mid z_{l}, c \leq p_{o l}\right)=\operatorname{Pr}\left(c \leq b_{l}^{-1}(p) \mid z_{l}, c \leq p_{o l}\right) \\
& =F\left(b_{l}^{-1}(p) \mid z_{l}, c \leq p_{o l}\right)=F\left(c \mid z_{l}, c \leq p_{o l}\right)=\frac{F\left(c \mid z_{l}\right)}{F\left(p_{o l}\right)}
\end{aligned}
$$

for all $p \in\left[\underline{p}_{l}, p_{o l}\right]$. The density of the observed bids $g_{l}^{*}(\cdot)$ is therefore:

$$
\begin{aligned}
g_{l}^{*}(p) & =\frac{d}{d p}\left[G_{l}^{*}(p)\right]=\frac{d}{d p}\left[\frac{F_{l}\left(b_{l}^{-1}(p)\right)}{F\left(p_{0}\right)}\right] \\
& =\frac{1}{b_{l}^{\prime}(c)} \frac{f_{l}\left(b^{-1}(p)\right)}{F\left(p_{0}\right)}=\frac{1}{b_{l}^{\prime}(c)} \frac{f_{l}(c)}{F\left(p_{0}\right)}
\end{aligned}
$$

for all $p \in\left[\underline{p}_{l}, p_{o l}\right]$.

Substituting (5) and (6) in (4), we obtain:

$$
\frac{1}{\left(I_{l}-1\right)} \frac{1-G_{l}^{*}\left(p_{i l}\right) F\left(p_{o l}\right)}{g_{l}^{*}\left(p_{i l}\right) F\left(p_{o l}\right)}=p_{i l}-c_{i l}
$$


where $p_{i l}=b_{l}\left(c_{i l}\right)$ is the equilibrium strategy. The strategy derivative $b_{l}^{\prime}(\cdot)$, the cost distribution $F_{l}(\cdot)$ and the cost density $f_{l}(\cdot)$ have been eliminated simultaneously. The unknown cost is now defined as a function of observable variables: the number of bidders, the bid, the density and the distribution of the observed bids.

We use, hereafter, the notation $\xi_{l}\left(p_{i l}\right)$ for the inverse of the bid function defined by:

$$
\xi_{l}\left(p_{i l}\right)=p_{i l}-\frac{1}{\left(I_{l}-1\right)} \frac{1-G_{l}^{*}\left(p_{i l}\right) F\left(p_{o l}\right)}{g_{l}^{*}\left(p_{i l}\right) F\left(p_{o l}\right)}
$$

for $p_{i l} \in\left[\underline{p}_{l}, p_{o l}\right]$.

Proposition 1 Let $I \geq 2$. Let $G_{l}(\cdot)$ be an absolutely continuous distribution defined on the interval $\left[\underline{p}_{l}, \bar{c}_{l}\right]$. Then there exists a distribution of bidders' private costs such that $F_{l}(\cdot)$ is the corresponding distribution of equilibrium bids in a first-price sealed-bid auction with independent private values and a binding reserve price if and only if: $C 1$ : The bids are independent and identically distributed as $G_{l}(\cdot)$. C2: The function $\xi_{l}(\cdot)$ defined in $(7)$ is strictly increasing on $\left[\underline{p}_{l}, \overline{p 0}_{l}\right]$ and its inverse is differentiable on $\left[\underline{c}_{l}, \overline{p 0}_{l}\right] \equiv\left[\xi_{l}\left(\underline{p}_{l}\right), \xi_{l}\left(\overline{p 0}_{l}\right)\right]$. Moreover, when $F_{l}(\cdot)$ exists it is unique with support $\left[\underline{c}_{l}, \bar{c}_{l}\right]$ and satisfies $F_{l}\left(c_{i l}\right)=G_{l}\left(\xi_{l}^{-1}\left(c_{i l}\right)\right)$ for all $i \in\left[1, \ldots, I_{l}\right], l \in[1, \ldots, L]$ (where $L$ is the number of auctions). In addition, $\xi_{l}(\cdot)$ is the inverse of the equilibrium strategy $b_{l}(\cdot): \xi_{l}(\cdot)=b_{l}^{-1}(\cdot)$.

P roof. Adapt the proof of theorem 1 in Guerre, Perrigne and Vuong [2000]. Details can be provided upon request.

Assuming that the firms behave as predicted by the theory (section 3 ), proposition 1 establishes that the latent cost distribution $F_{l}\left(c_{i l}\right)$ is identified from the distribution of the observed bids. To estimate the latter we use a nonparametric statistical method, which avoids picking an arbitrary functional form to describe the distribution. Our estimator is based on the kernel method (see Härdle [1990, 1991], Simonoff [1996] or Yatchew [1998]).

To recover the cost distribution from (7), we first need to estimate the density and cumulative 
conditional distribution functions of the observed bids.

$$
\widehat{g}^{*}\left(p \mid z_{b}\right)=\frac{\frac{1}{L h_{g z} h_{g p}} \sum_{l=1}^{L} \frac{1}{I_{l}^{*}} \sum_{i=1}^{I_{l}^{*}} K\left(\frac{z-Z_{l}}{h_{g z}}\right) K\left(\frac{p-P_{i l}}{h_{g p}}\right)}{\frac{1}{L h_{g z}} \sum_{l=1}^{L} K\left(\frac{z-Z_{l}}{h_{g z}}\right)}
$$

where $\left\{\left(P_{i l}, Z_{l}\right)\right\}_{l=1, \ldots L}^{i=1, \ldots, I_{l}^{*}}$ is the sample of independent observations from the distribution of $(P, Z), L$ is the number of auctions, $I_{l}^{*}$ is the number of observed bidders in auction $l, K(\cdot)$ is a kernel, and $h_{g z}$ and $h_{g p}$ are the bandwidths. The characteristics of the auction that we use to estimate the bid density are denoted z. We use the "quartic" or "biweight" Kernel defined as :

$$
K(u)=\frac{15}{16}\left(1-u^{2}\right)^{2} \mathbb{I}(|u| \leq 1)
$$

except for the single index where we use a kernel of order 4 . As the estimate inherits the properties of the kernel, we have chosen our kernel such that it is positive, defined on a bounded support and differentiable everywhere on the support. Our estimate is therefore a positive function, bounded and differentiable. The choice of a kernel does not really matter for the global accuracy of the estimation so it "should be chosen based on other issues, such as ease of computation or properties of the estimate" (Simonoff [1996]). The bandwidths are determined by the so-called "rule of thumb" ${ }^{13}$. We find $h_{g p}=1.50$ and $h_{g z}=27.92$. More information about the kernel and the bandwidths are provided in the appendix.

The conditional distribution $G^{*}(\cdot \mid \cdot)$ is estimated with the following estimator:

$$
\widehat{G}^{*}\left(p \mid z_{b}\right)=\frac{\frac{1}{L h_{G}} \sum_{l=1}^{L} \frac{1}{I_{l}^{*}} \sum_{i=1}^{I_{l}^{*}} \mathbb{I}\left(p_{i l} \leq p\right) K\left(\frac{z-Z_{l}}{h_{G}}\right)}{\frac{1}{L h_{G}} \sum_{l=1}^{L} K\left(\frac{z-Z_{l}}{h_{G}}\right)} .
$$

The bandwidth, set by the rule of thumb, is equal to $h_{G}=24.34$.

We then estimate the term to evaluate the truncated density and distribution of bids. The number of potential bidders is unknown with a binding reserve price. A natural estimator for the potential number of bidders $I$ is $\widehat{I}=\max _{\ell} I_{\ell}^{*}$. Using $E\left(I_{\ell}^{*} \mid z_{\ell}\right)=I \phi\left(z_{\ell}\right)$, and solving for $\phi\left(z_{\ell}\right)$, we obtain for any

\footnotetext{
${ }^{13}$ The original rule of thumb was derived assum ing that the underlying density was gaussian. But this gaussian reference rule can easily be converted to a rule based on a quartic kernel function: the constant is then 2.78 instead of 1.06 . See Simonoff [1996, pages 45-46].
} 
value $z$

$$
\hat{\phi}(z)=\frac{\frac{1}{\hat{I} L h_{G}} \sum_{\ell=1}^{L} I_{\ell}^{*} K\left(\frac{z-Z_{l}}{h_{G}}\right)}{\frac{1}{L h_{G}} \sum_{l=1}^{L} K\left(\frac{z-Z_{l}}{h_{G}}\right)}
$$

using a kernel estimator for the nonparametric regression.

We can now deduce the pseudo-costs:

$$
\widehat{c}_{i l}=p_{i l}-\frac{1}{(\widehat{I}-1)} \frac{1-G_{l}^{*}\left(p_{i l}\right) F\left(p_{o l}\right)}{g_{l}^{*}\left(p_{i l}\right) F\left(p_{o l}\right)}
$$

The rent for firm $i$, if it is the winner in auction $l$, is given by:

$$
\widehat{r e n t}_{i l}=\frac{1}{(\widehat{I}-1)} \frac{1-G_{l}^{*}\left(p_{i l}\right) F\left(p_{o l}\right)}{g_{l}^{*}\left(p_{i l}\right) F\left(p_{o l}\right)} .
$$

The rent decreases with the number of potential bidders and with the hazard rate.

The contracts for tender in different parts of the City differ by various characteristics: traffic, road width, territory size, distance to the dump site, and, over time, by the state of the arts in snow removal. The characteristics $z_{l}$, the conditioning variables of the bid hazard rate, should account for this heterogeneity. As we are restricted regarding the number of variables we can use in the estimation, we have to resort to a variable reduction technique. ${ }^{14}$

To aggregate the dimensions of $x$, where $x$ represents the characteristics of the contracts, we use a single-index model $z=x \beta$. This implies that the conditional mean function of the observed bids with respect to the characteristics of the contracts has the form:

$$
E(p \mid x)=E(p \mid x \beta)=H(x \beta)
$$

where $\beta$ is an unknown constant vector of dimension $k=3$ (the same dimension as $x$ ), $H$ is an unknown function and the quantity $x \beta$ is called a single-index. The inferential problem in (11) is to estimate both $\beta$ and $H$ from observations of $(p, x)$. We further assume that the conditional density and distribution

\footnotetext{
14 "Although many estimation schemes, including kernel [...] directly generalize to higher dimensions, practical implementation lags behind this theoretical fact. [...] It seems likely that the most useful approach for higher dimensional data is dimension reduction of some sort." (Simonoff [1996]).
} 
of the observed bids with respect to the characteristics of the contracts are functions of the same single index: $G^{*}(p \mid x)=G^{*}(p \mid x \beta)$ and $g^{*}(p \mid x)=g^{*}(p \mid x \beta)$. This approach allows the data to provide the information on the conditional relation between bids and contract characteristics. This reduction method is far preferable, say to a principal component analysis that would only exploit the information provided by the characteristics of the contracts.

To estimate $\beta$ and $H$ from observations of $(p, x)$, we use a direct semiparametric estimator that is computationally convenient since it does not require solving an optimization problem and is noniterative. The weighted average derivative of the conditional mean function of the observed bids with respect to the characteristics of the contracts with weight function $W$, denoted $\delta=E\left[W(X) \frac{\partial E[p \mid x]}{\partial x}\right]$, is proportional to $\beta$. Using this property we are able to estimate $\beta$ up to a scale and to deduce the function H. Powell, et al. [1989] give conditions under which $\widehat{\delta}$ is a consistent estimator of $\delta$ and $L^{1 / 2}(\widehat{\delta}-\delta)$ is asymptotically normally distributed with mean 0 . The estimator of $\delta$ is observationally equivalent to $\beta$ up to scale normalization. The estimator of $\delta$, adapted to our dataset where the number of bids exceeds the number of contracts (since more than one firm bids to win each contract), is:

$$
\widehat{\delta}=\frac{-2}{L} \sum_{l=1}^{L} \frac{1}{I_{l}^{*}} \sum_{i=1}^{I_{l}^{*}} p_{i l} \frac{\partial f_{l}\left(x_{l}\right)}{\partial x}
$$

The characteristics of the contracts, denoted $x$, form a vector of dimension $3\left(x^{1}, x^{2}, x^{3}\right)$. Each contract is characterized by the length of the territory, the distance to the snow dump and a trend variable that captures technological progress that took place over the period. It follows from standard properties of kernel density estimators that $\hat{f}_{l}$ is a consistent estimator of $f_{l}$. The formulae for $\hat{f}_{l}$ is:

$$
\widehat{f}_{l}(x)=\frac{1}{(L-1) h_{1} h_{2} h_{3}} \sum_{\substack{j=1 \\ j \neq l}} K_{\delta}\left(\frac{x^{1}-x_{j}^{1}}{h_{1}}\right) K_{\delta}\left(\frac{x^{2}-x_{j}^{2}}{h_{2}}\right) K_{\delta}\left(\frac{x^{3}-x_{j}^{3}}{h_{3}}\right)
$$

In (13), we estimate the multivariate kernel function as the product of one-dimensional kernel functions. The choice of the kernel $K_{\delta}$ and the bandwidth $h=\left(h_{1}, h_{2}, h_{3}\right)$ are explained in the appendix. Moreover, $\frac{\partial f_{l}\left(x_{i}\right)}{\partial x}$ is estimated consistently by $\frac{\partial \hat{f}_{l}\left(x_{i}\right)}{\partial x}$. For example, for the derivative with respect to the first 
component of the single index:

$$
\frac{\widehat{\partial f_{l}\left(x_{l}\right)}}{\partial x^{1}}=\frac{1}{(L-1) h_{1}^{2} h_{2} h_{3}} \sum_{\substack{j=1 \\ j \neq l}} K_{\delta}^{\prime}\left(\frac{x^{1}-x_{j}^{1}}{h_{1}}\right) K_{\delta}\left(\frac{x^{2}-x_{j}^{2}}{h_{2}}\right) K_{\delta}\left(\frac{x^{3}-x_{j}^{3}}{h_{3}}\right)
$$

We are then able to construct our single index that aggregates the information about the contracts as follow:

$$
z=x \beta
$$

Finally, a nonparametric estimate of the cost distribution can be obtained using the pseudo-sample $\left(\widehat{c}_{i l}, z_{l}\right), i=1, \ldots, I_{l}^{*}, l=1, \ldots, L$. If $f(c, z)$ denotes the joint density of $(C, Z)$ and $f_{z}(z)$ denotes the marginal density of $Z$, then the conditional cost density estimator is given by:

$$
\hat{f}(c \mid z)=\frac{\frac{1}{L h_{f z} h_{f c}} \sum_{l=1}^{L} \frac{1}{I_{l}^{*}} \sum_{i=1}^{I_{l}^{*}} K\left(\frac{z-Z_{l}}{h_{f z}}\right) K\left(\frac{c-c_{i 2}}{h_{f c}}\right)}{\frac{1}{L h_{f z}} \sum_{l=1}^{L} K\left(\frac{z-Z_{l}}{h_{f z}}\right)}
$$

Using "quartic" kernel as in (8) and the same 'rule of thumb', we obtain the bandwidths $h_{f c}=1.52$ and $h_{f z}=27.92$ for the $f$ function.

\section{Results}

We apply the nonparametric estimation method outlined in the preceding section to our auction model and the 457 observed bids for snow removal contracts with the City of Montreal. First, we present the estimated conditional bid density functions and the inferred conditional cost distributions of the private contractors. Second, we discuss economies of scale and their exploitation by the City. Third, we turn to the implicit informational rents earned by the private contractors. Finally, we discuss whether the reserve price is set optimally or not. In each case, we confront our results with the implications of the theoretical model, and we evaluate the actions taken by the City from that perspective. 


\subsection{Estimated Bid Density and Cost Density Functions}

We begin by presenting the estimated bid densities conditional on various levels of the characteristic $z$. Figure 2 shows a selected number of estimated bid densities $g(\cdot \mid z)$ plotted side by side ${ }^{15}$. The densities are unimodal and quite symmetric in shape (although slightly skewed). The mode appears to decrease monotonically with z. This result indicates that bids decrease with territory size and technological progress since high positive values of $z$ correspond to more recent years and larger territory sizes. In addition, it is apparent that the variance of the bids decreases as $z$ increases.

The knowledge of the bid functions allow us to construct the pseudo-sample of costs, using $(9)$. We find that, for a given $z$, the estimated cost schedule $\xi_{l}(\cdot)$ is indeed an increasing function of the bids, as required by proposition $1^{16}$. The conditional cost density functions presented in Figure 3 have a shape quite similar to the conditional bid density functions (unimodal and slightly skewed). Figure 3 shows that an increase in territory size and technological progress (everything else equal) leads to a reduction in the mean and the variance of the cost of snow removal by private contractors. This may signal the presence of unexploited economies of scale, returns to scale in the industry and unused capacity of production.

\subsection{Expected Bids and Costs}

In Figure 4, we present the conditional expectation of costs and bids (estimated semiparametrically) which highlight how the bids and the costs change with $z$. Since high positive values of $z$ correspond to more recent auctions and larger territory sizes, it appears that the combined influence of the size of the territory and technological progress has reduced the bids and the costs strongly at the beginning of the period and at a slower pace afterwards. To separate the respective role of territory size and technological progress we assess the relative sensitivity of $\mathrm{z}$ to length, distance, and technological progress. For that, we go back to the construction of the single index $z=x \beta$ that aggregates the dimension of the contract characteristics $x$ (length, distance, technological progress). The coefficients in $\delta$, are observationally

\footnotetext{
${ }^{15}$ The values of $z$ are chosen along a grid of values constructed on $[\underline{z}, \bar{z}]$. We present the 25 th, 50 th and 75 th percentile.

${ }^{16} \mathrm{Graphs}$ of the $\xi_{l}(\cdot)$ functions are available upon request.
} 
equivalent to those in $\beta$ up to scale normalization, and give the relative sensitivity of $z$ to the vector $x$. We have found $\widehat{\delta}=(1.000 ;-4.037 ; 20.126)$. It follows that $\mathrm{z}$ is 20 times more sensitive to technological progress than to the length of the territory, i.e. the effect of technological progress that takes place in one year is equivalent to an increase of 20 kilometers in the length of the territory. It suggests that the increase in territory size alone does not explain much of the reduction in costs and bids. The coefficients of the single index also indicate that $\mathrm{z}$ is four times more sensitive to the distance to the snow dump than to the length of the territory and therefore suggests that the reduction of price and costs from larger territories is partially outweighed by an increase in the transportation cost to the snow dump because larger territories imply larger distance to the snow dump ${ }^{17}$. Moreover, it is very likely that some technological progress has been induced by larger territory size. As a matter of fact, increasing the territory size has forced firms that did not already use efficient equipment to upgrade their machinery in order to meet the deadlines imposed by the City to clear the school and hospital areas. This interpretation is corroborated by results indicating that the variance of costs was larger at the beginning of the period than at the end of the period.

The conjecture that the increase in territory size triggered technological progress is also reinforced by Canadian multifactor productivity. On one hand, for the period 1988 to 2000, the annual growth rate of multifactor productivity has been between $0.4 \%$ for business sector-services and $1.7 \%$ in manufacturing

\footnotetext{
17 Another way to get some insights into the relative contributions of each factor would be to use our semiparametric estimate of the conditional expectation of bids (see Figure 4 ) to choose a functional form for $H$ and then reestimate parametrically the conditional expectation of bids. We chose a quadratic form that seems quite close to the form given by Figure 4 except for the inflexion point that is not taken into account with a quadratic form. We found that $\hat{\beta}$ up to a scale is equal to $\hat{\beta}=(1,-2.04,4.01)$ and that the estimate of the function $H$ is $\hat{H}(z)=\widehat{E(p \mid z)}=11.52-\mathbf{0 . 2 9} z+\mathbf{0 . 0 1} z^{2}$ where $z=x \beta=\beta_{1} L+\beta_{2} D+\beta_{3} T$. The parametrically estimated single index is quite different from the semiparametrically estimated single index whose coefficients are respectively $(1,-4.04,20.13)$. It indicates that a quadratic function is not flexible enough to represent the function $H$. It also indicates that the following results derived from the parametric estimation have to be interpreted with caution. The derivative of parametrically estimated conditional bids with respect to territory size, distance and time are respectively $-0.04,0.43$ and -0.41 . Therefore, each additional kilometer of territory size reduces the bid by 4 cents per meter of streets cleared of snow, while each year the growth in technical progress reduces the bids by 41 cents per meter of snow clearing. Considering that the mean territory size increased by 7 kilometers between 1990 and 1995 and that the smallest territory (auctioned in 1990) was 23 kilometers shorter than the largest one (auctioned in 1996), the price impact of changes in territory size has been moderate. As a matter of fact, if we compare the average for the years 1995 and 1990 , we find that bids would have decreased by roughly $\$ 1.30$ as the result of the 7 kilometer increase in size of the average territory, the 4 years of technological progress and of the $1.45 \mathrm{kilometer} \mathrm{increased} \mathrm{distance}$ to the snow dump. Most of the decrease in bids came from technological progress since the increase in territory size cut bids by only 28 cents while technological progress reduced bids by $\$ 1.64$ over the four years (or roughly by $3.5 \%$ annually) and the increase to the snow dump increased the bids by 62 cents. When comparing the average bids for these two years, we find that in fact bids have decreased by nearly $\$ 2$, from $\$ 13.52 / \mathrm{m}$ to $\$ 11.53 / \mathrm{m}$. Therefore, we explain $65 \%$ of that reduction in bids with our least-squares estimates. In both cases -with the semiparametric and the parametric estimatestechnological progress explains most of the reduction in bids.
} 
industries according to a Statistics Canada survey ${ }^{18}$. On the other hand, expected bids and costs conditional on $z$ have decreased by approximately $24 \%$ over our period of study ${ }^{19}$. In other words, bids and costs have diminished by roughly $4 \%$ a year following changes in $z$, nearly all of which came from technological progress according to the coefficients in our single index. This is much bigger than the Canadian figures and suggests technological innovations beyond the "normal" exogenous technological progress in the industry. In this sense, we can say that increasing the territory size has been a successful policy, as shown in Figure $4^{20}$.

\subsection{Informational Rents}

It would be unwise to increase territory size if cost reductions were offset by increased rents due to either lower competition or a larger variance of costs among potential suppliers. As shown in Figure 5 , the informational rent ${ }^{21}$ earned by a contract winner is around 0.67 cents per meter of snow cleared over the winter on average, or about $6.7 \%$ of the winner's cost. Therefore, the cost of asymmetric information turns out not to be excessive and its evolution is no cause for concern. The rent remained relatively constant over the periods $[1990-1992],[1993-1996]$ and $[1997-1998]$ with respectively $0.70,0.62$ and 0.71 cents per meter. If we compare the rents for similar territories (put up to tender every four years), we generally find that the rent falls with the length of the territory ${ }^{22}$. But factors such as a change in reserve price or in the variance of costs of the potential bidders also affect the rents. Both have fallen and also explain the reduction in rent. The correlation between the estimated rent and the

\footnotetext{
${ }^{18}$ We used The Daily from Statistics Canada of Tuesday May 22, 2001 which presents data on multifactor productivity for 1988-2000. The statistics have been computed using the matrices 9456-9458 and 9460-9483 in Cansim.

${ }^{19}$ When we estimate nonparametrically the conditional expectation of bids with respect to $z$, we find a maximum of $13.26 \$ / \mathrm{m}$ at the beginning of the period and a minimum of $10.08 \$ / \mathrm{m}$ at the end of the period. For the conditional expectation of costs with respect to $\mathrm{z}$, the maximum at the begining of the period is $12.68 \$ / \mathrm{m}$ and the $\mathrm{minimum}$ at the end of the period is $9.70 \$ / \mathrm{m}$. Therefore the expected bids and costs for the City have decreased by approximately $24 \%$ over the period.

${ }^{20}$ The reduction of costs on all territories also suggests that firms were able to reap even more the benefits of better equipment on larger territories. It would therefore suggest that firms were able to enjoy returns to scale and maybe increase their capacity of production toward full capacity for each territory.

${ }^{21}$ Figure 5 shows average winner's bids and estimated winner's costs over the sample period. The informational rent is the area between these two curves.

${ }^{22}$ We have compared the year 1990 with the year 1995 when the 1990 contracts were renewed. Between these two dates, the average territory size increased from $32 \mathrm{~km}$ to $39 \mathrm{~km}$ and the rents fell from $0.76 \$ / \mathrm{m}$ to $0.42 \$ / \mathrm{m}$ on average. When we perform the same exercise for the years 1991 and 1996, and 1992 and 1997 respectively, we also find in both cases the territory size increased while rents dropped. Finally, between 1993 and 1998, the average rent decreased despite a constant territory size.
} 
variance of cost is positive which is consistent with the theoretical model ${ }^{23}$. Table 4 gives the average of the winner's informational rent in different periods, along with a number of auction characteristics. The data has been grouped into three periods of three years each, except for the last period, which includes only two years because it coincides with the end of the sample. ${ }^{24}$

\subsection{Optimal Reserve Prices}

The optimal reserve price, denoted $p_{o l}^{*}$ should be chosen to minimize the expected cost to the buyer. It allows to capture part of the informational rent that goes to the winner by restricting the number of participants. It is defined by

$$
p_{o l}^{*}=c_{o l}-\frac{F\left(p_{o l}^{*} \mid z_{l}\right)}{f\left(p_{o l}^{*} \mid z_{l}\right)}
$$

where $c_{o l}$ is the cost to the City of Montreal to perform the activity itself. Since we don't know $c_{o l}$, we compute $c_{o l}$ from equation (17) assuming that the reserve prices are optimally chosen. We find that the implicit cost for the City $c_{o l}$ is nearly equal to the reserve price (with a difference that does not exceed $1 \%$ ) and is $14.4 \%$ higher than the average cost of the private suppliers (see Table 5 ). It indicates that the cost of snow removal for taxpayers would increase by at least $14.4 \%$ if the City of Montreal was not auctioning off the services. The percentage difference of how much it would cost the City and the private suppliers varies between $6 \%$ and $48 \%$ (see Table 5 ). We can therefore conclude that the City has a large comparative disadvantage on some territories ${ }^{25}$.

Finally, these results suggest that if the Cost for the City is indeed consistently $14.4 \%$ higher on average than its suppliers, the reserve prices are nearly optimally set over the whole period 1990-1998 and that the City has kept up successfully with the reduction of production cost ${ }^{26}$. It is true that we actually don't know if the City cost has indeed changed according to its supplier costs. However, it is

\footnotetext{
${ }^{23}$ When the firms are more alike, the variance of costs falls and the informational rent is reduced. We find a positive correlation of 0.59 .

${ }^{24}$ As already mentioned, for historical reasons, no contracts were offered in 1994, which explains why the $1993-1996$ period is indeed a three year period contract.

${ }^{25}$ However, it is possible that the reserve prices are not optimally chosen. If the cost is on average less than $14.4 \%$ higher for the City than for its suppliers, then the reserve prices should be lower. Otherwise they are too much binding and ought to be increased.

${ }^{26}$ The reserve price depends on the cost of production of the City and not of the supplier costs. However, we have just implicitly assumed that the supplier costs are very correlated with the City cost. As a matter of fact, both the City and its suppliers have benefited from the same technological progress.
} 
likely that the gap between the City cost and its suppliers remained constant ${ }^{27}$. As a matter of fact, the City performs itself some of the activity and therefore has faced the same changes as its suppliers over time.

\section{Conclusion}

We have evaluated the performance of snow removal procurement from data on bids, the number of bidders and some of the characteristics of 457 contracts offered for tender by the City of Montreal between 1990 and 1998. Using nonparametric estimation techniques adapted from Guerre et al. [2000], we were able to compute bid density functions conditional on contract characteristics, and to infer the cost distributions of the firms that do contractual work for the City, as well as the informational rents they earn. Both the bid and the cost densities are unimodal, and their means and variances depend on contract characteristics. The latter have been summarized using a single index estimated semiparametrically adapting the method of Powell et al. [1989] and therefore exploiting the relationship between the bids and the characteristics.

Bids and costs have decreased over the sample period while informational rents remained relatively constant. Our results were shown to be compatible with standard received theory of competitive auctions: there is a positive correlation between costs and bids and rents increase with the variance of costs.

Both the model and the techniques used to obtain the results rely on the assumption of perfect competition. We did not adopt this assumption without some strong a priori indications that it was a reasonable approximation of reality. We discussed the issue with City officials and private contractors who, respectively, congratulated themselves and deplored that competition was strong. Moreover, the City of Montréal (with a population of one million) is only one of several municipalities in an urban community of three million people, that use the services of private entrepreneurs for snow removal. The reservoir of entrepreneurs is even larger as their activities are not limited to snow removal. Firms as

\footnotetext{
${ }^{27}$ The City might have higher costs than its suppliers because it performs many activities and does not specialize particularly in snow removal. Moreover, the City might face more constraints (in particular labour constraints) than its suppliers.
} 
different as paving contractors, landscape contractors, lawn mowers, excavating and building firms can provide snow removal services during the winter season by making minor additions to their equipment. Finally, the data indicates that the number of actual bidders was consistently at around seven or eight, in most auctions. Our results tend to confirm this a priori information: rents left in the hands of the winning bidders were found to be consistently low over the sample period.

Although working hypotheses can always be challenged, we feel confident that our investigation of policy issues is well-grounded. The evidence is that the City has effectively exploited the opportunities it had to reduce the cost of snow removal services. The bids for, and the underlying costs of, snow removal have declined over the period 1990 to 1998 . It appears that the City was not passive in that process. Within the framework of competitive supply auctions, there were at least two basic ways in which it was able to reduce the amount the taxpayer had to pay for snow removal services. First, it organized the work in such a way as to reduce the cost of performing the service. The evidence suggests that increasing territory size has triggered technological innovations beyond the "normal" exogenous technological progress in the industry. Second, it defined the contracts so as to make the pool of bidders more homogeneous, thus reducing cost variance and cutting the rent left in the hands of the winner. There is some evidence that the cost variance was reduced over the sample period by making the territories more homogeneous. Further the reserve prices appeared binding and have been decreased adequately to keep up with the reduction in the cost of snow removal.

Several other aspects of the City's procurement policies would be worth investigating. For example, it is possible that the individual costs of private contractors are not entirely independent but might have a common component due to meteorological forecasts or other factors. By stipulating how weather risks are shared by the City and the contractors, the City might influence the bidding. Another interesting auction management question would be to ask whether the City should keep for itself any territory for snow removal or whether it should contract all of them to the private sector. Finally, we could investigate whether the snow clearance and its transportation should be a joint or two separate procurements put up for auction. We leave that for further work.

We acknowledge the support of SSHRC. The first author also thanks CIRANO for its financial support during part of the completion of this work. 


\section{References}

Donald, S.G., Paarsch, H.J., 1993. Piecewise Maximum Likelihood Estimation in Empirical Models of Auctions. International Economic Review 34, 121-148.

Donald, S.G., Paarsch, H.J., 1996. Identification, Estimation, and Testing in Parametric Empirical Models of Auctions within the Independent Private Value Paradigm. Econometric Theory 12, 517-567.

Elyakime, B., Laffont, J.J., Loisel, P., Vuong, Q., 1994. First-Price Sealed-Bid Auctions with Secret Reservation Prices. Annales d'Economie et de Statistique 34, 115-141.

Flambard, V., I. Perrigne, 2004. Asymmetry in Procurement Auctions: Evidence from Snow Removal Contracts. Mimeo, Grant MacEwan College.

Florens, J.P., Hugo, M.A., Richard, J.F., 1997. Game Theory Econometric Models: Application to Procurements in the Space Industry. European Economic Review 41, 951-959.

Gasser, T., Mueller, H-G, Mammitzsch, V., 1985. Kernels for Nonparametric Curve Estimation. Journal of the Royal Statistical Society B 47(2), 238-252.

Guerre, E., Perrigne, I., Vuong, Q., 2000. Optimal Nonparametric Estimation of First-Price Auctions. Econometrica 68(3), 525-574.

Jofre-Bonet, M. and M. Pesendorfer, 2003. Estimation of a Dynamic Auction Game, Econometrica $71,1443-1489$.

Härdle, W., 1990. Applied Nonparametric Regression, Econometric Society Monographs, Cambridge, Cambridge University Press.

Härdle, W., 1991. Smoothing Techniques with Implementation in S, Springer Series in Statistics, New York, Springer-Verlag.

Härdle, W. and A. B. Tsybakov, 1993. How sensitive Are Average Derivatives?. Journal of Econometrics, 58, 31-48.

Hassani, S., Sarda, P. Vieu, P., 1986. Approche non paramétrique en théorie de la fiabilité: revue bibliographique. Revue de Statistiques Appliquées 35(4), 27-41.

Krasnokutskaya, H., 2002. Identification and Estimation in Highway Procurement Auctions under Unobserved Heterogeneity. Working Paper, Yale University. 
Laffont, J.J., Ossard, H., Vuong, Q., 1995. Econometrics of First-Price Auctions. Econometrica 63, 953-980.

Laffont, J.J. Vuong, Q., 1993. Structural Econometric Analysis of Descending Auctions. European Economic Review 37, 329-341.

Li, T., I. Perrigne and Q. Vuong, 2002. Structural Estimation of the Affiliated Private Values Model. Rand Journal of Economics, 33, 171-193.

McAfee, R. P., McMillan, J., 1986. Bidding for Contracts: A Principal-Agent Analysis. Rand Journal of Economics 17(3), 326-338.

McAfee, R. P., McMillan, J., 1987. Auctions and Bidding. Journal of Economic Literature 25, 699-738.

Paarsch, H. J., 1992. Deciding between the Common and Private Value Paradigms in Empirical Models of Auctions. Journal of Econometrics 51, 191-215.

Powell, J.L., J.H. Stock, and T. M. Stoker, 1989. Semiparametric Estimation of Index Coefficients, Econometrica, 57(6), 1403-1430.

Powell, J. and T. M. Stocker, 1996. Optimal Bandwidth Choice for Density-Weighted Averages. Journal of Econometrics, 75, 291-316.

Riley, J. G., Samuelson, W. F., 1981. Optimal Auctions. American Economic Review 71(3), 381-92. Simonoff, J. S., 1996. Smoothing Methods in Statistics. Springer Series in Statistics, New York, Springer-Verlag.

Yatchew, A., 1998. Nonparametric Regression Techniques in Economics. Journal of Economic Literature 36, 669-721. 


\section{Appendix: Construction of the Single Index}

We use a single index model to take into account the heterogeneity across the tracts as we explained before. We present our choices for the kernel bandwidth and the optimal bandwidth hereafter following Härdle and Tsybakov (1993) and Powell and Stocker (1996). The order of the kernel (denoted P) should be even and should be a function of the number of variables (denoted $\mathrm{k}$ ) that need to be aggregated. More specifically ${ }^{28}$

$$
P \geq \frac{(k+3)}{2}
$$

We use the kernel of order 4 developed by Gasser, Mueller and Mammitzsch (1985):

$$
K_{\delta}(u)=\frac{105}{64} *\left(1-5 * u^{2}+7 * u^{4}-3 * u^{6}\right) \mathbb{I}(|u| \leq 1)
$$

The asymptotically optimal bandwidth has the form

$$
h=h_{0} L^{-2 /(2 P+k+2)}=h_{0} L^{-1 / 6.5}
$$

We will use a plug-in estimator of the optimal bandwidth as described in Powell and Stocker (1996) but we have to adapt the formulae for our case where the number of bids differ from auction to auction. The estimator of the vector $h_{0}$ is

$$
h_{0}=\left[\frac{(k+2) \widehat{Q}}{P \widehat{S}^{2}}\right]^{1 /(2 P+k+2)}=\left[\frac{5 \widehat{Q}}{4 \widehat{S}^{2}}\right]^{1 / 13}
$$

where with the same notation as before the component $\mathrm{q}=1,2,3$ of $\mathrm{Q}$ denoted by a superscript is given by

$$
\widehat{Q^{q}}=\frac{2}{L(L-1)} * \frac{1}{\left(h_{L}^{1}\right)\left(h_{L}^{2}\right)\left(h_{L}^{3}\right)} \sum_{l=1}^{L-1} \frac{1}{n_{l}^{*}} \sum_{i=1}^{\operatorname{Max}\left(n_{l}^{*}\right)} \sum_{j=l+1}^{L}\left[K_{\delta}^{\prime}\left(\frac{x_{l}^{q}-x_{j}^{q}}{h_{L}^{q}}\right) * \prod_{\substack{m=1 \\ m \neq q}}^{3} K_{\delta}\left(\frac{x_{l}^{m}-x_{j}^{m}}{h_{L}^{m}}\right) *\left(b_{i l}-b_{i j}\right)\right]^{2}
$$

\footnotetext{
${ }^{28}$ See Härdle and Tsybakov page 36, assumptions A1 and A2.
} 
and

$$
\widehat{S}=\frac{\delta\left(\tau h_{n 1}\right)-\delta\left(h_{n 1}\right)}{\left(\tau h_{n 1}\right)^{P}-\left(h_{n 1}\right)^{P}}
$$

where $\tau$ is a positive number different from 1 (we choose 2 ) and $\delta\left(h_{n 1}\right)$ is the estimator of $\delta$ obtained with the bandwidth $h_{n 1}$. The vector $h_{n 1}$ must satisfy proposition 4.2 of Powell and Stocker and must be such that

$$
\lim _{L \rightarrow \infty} h_{L}=0 \text { and } \lim _{L \rightarrow \infty} L *\left(h_{L}\right)^{c}=\infty \text { with } c=\max (\eta+2 k+4,2 P+k+2) \text { for } \eta>0
$$

We choose $\eta=1$ and then we have $c=13$. The initial value for the bandwidth $h_{L}$ satisfies the above condition $^{29}$ and is equal to $h_{L}=s t d c(x) * L^{-1 / 26}=(0.854 ; 0.854 ; 0.854)$. Using the formulae (18), we find for the optimal bandwidth $h=(1.414 ; 1.298 ; 1.173)$. Our estimator of the single index will then be a consistent estimator of $\delta$ and $L^{1 / 2}(\widehat{\delta}-\delta)$ is asymptotically normally distributed with mean 0 . The estimator $\delta$ of the single index up to a scale is found to be equal to $\widehat{\delta}=(1.000 ;-4.037 ; 20.126)$.

Choice of Kernels and Bandwidths for the Estimation of the Densities and Distributions of Bids and Costs

The choice of the kernel does not really matter as long as the kernel is defined on a compact support and is differentiable on its support. We choose the biweight kernel

$$
K(u)=\frac{15}{16}\left(1-u^{2}\right)^{2} \mathbb{I}(|u| \leq 1)
$$

The choice of a bandwidth requires, however, more attention. In particular, a too large bandwidth tends to oversmooth the estimated density, while a too small bandwidth tends to undersmooth the estimated density. Moreover, a large bandwidth tends to increase the bias of the estimator while a small bandwidth tends to increase its variance. Finally, the bandwidths define the uniform consistency rate of the estimators. Let $L=61$ be the number of auctions. We assume that the density $f(\cdot)$ admit $R$ bounded continuous derivatives. Because the kernel function has to be of order $R+1$, we assume

\footnotetext{
${ }^{29}$ Therefore, we allow $h_{L}$ to converge to 0 at a different rate than the optimal bandwidth as required in Powell and Stocker (page 311).
} 
$R=1$. The biweight kernel is of order 2. The bandwidths are of the following form for the first and second step of our estimator

$$
\begin{aligned}
& h_{G}=2.778 \sigma_{z}(61)^{-1 / 5}, h_{g p}=2.778 \sigma_{p}(457)^{-1 / 6} \\
& h_{g z}=h_{f z}=2.778 \sigma_{z}(L)^{-1 / 6}, h_{f p}=2.778 \sigma_{c}(457)^{-1 / 6}
\end{aligned}
$$

The constants are determined by the so-called rule of thumb. Namely, the constants are equal to $2.623 \times 1.06 \hat{\sigma}$, where $\hat{\sigma}$ is the empirical standard deviation of observations. The factor 2.623 is a correction due to the use of a biweight kernel instead of a Gaussian kernel (see Hardle (1991) for more information on bandwidths choice). We find the following values for the bandwidths

$$
h_{G}=24.34, h_{g p}=1.50, h_{g z}=h_{f z}=27.92, h_{f c}=1.52
$$


Table 1: Auction Data Summary 1

\begin{tabular}{cccclc}
\hline & $\begin{array}{l}\text { Average } \\
\text { of All }\end{array}$ & $\begin{array}{l}\text { Average } \\
\text { Winning }\end{array}$ & $\begin{array}{l}\text { Average } \\
\text { Territory }\end{array}$ & $\begin{array}{l}\text { Average } \\
\text { Distance }\end{array}$ & $\begin{array}{l}\text { Average } \\
\text { Number }\end{array}$ \\
& Bids & Bid & Size & to Snow Dump & of Actual \\
1990 & 13.52 & 12.11 & 31,920 & 2.35 & Bidders \\
1991 & 12.64 & 11.57 & 31,114 & 2.65 & 5.25 \\
1992 & 11.62 & 11.05 & 34,507 & 3.18 & 8.87 \\
1993 & 11.51 & 10.13 & 32,477 & 2.27 & 8.17 \\
1994 & -29 & - & - & - & 6.67 \\
1995 & 11.53 & 10.32 & 38,940 & 3.80 & - \\
1996 & 10.49 & 10.01 & 37,534 & 3.04 & 6.00 \\
1997 & 10.12 & 9.37 & 36,173 & 3.67 & 10.83 \\
1998 & 10.07 & 9.46 & 32,137 & 2.93 & 6.67 \\
\hline
\end{tabular}

Table 2: Auction Data Summary 2

\begin{tabular}{ccc}
\hline Year & $\begin{array}{l}\text { Number } \\
\text { of } \\
\text { Contracts }\end{array}$ & $\begin{array}{l}\text { Number } \\
\text { of Actual } \\
\text { Bidders }\end{array}$ \\
1990 & 8 & 42 \\
1991 & 15 & 133 \\
1992 & 6 & 49 \\
1993 & 3 & 20 \\
1994 & - & - \\
1995 & 8 & 56 \\
1996 & 12 & 72 \\
1997 & 6 & 65 \\
1998 & 3 & 20 \\
\hline
\end{tabular}

Table 3: Overall Statistics

\begin{tabular}{llllll}
\hline Variables & Mean & Std Error & Min. & Max. & \# of Obs. \\
\hline Bids (in $\$ / \mathrm{m}$ ) & 11.62 & 1.50 & 8.40 & 16.49 & 457 \\
Costs (in $\$ / \mathrm{m}$ ) & 11.15 & 1.52 & 5.88 & 14.31 & 457 \\
Winning Bids (in $\$ / \mathrm{m}$ ) & 10.73 & 1.18 & 8.40 & 12.88 & 61 \\
\# of Actual Bidders per Auction & 7.49 & 2.42 & 2 & 14 & 61 \\
\hline
\end{tabular}

\footnotetext{
${ }^{29}$ No auction was organized in 1994.
} 
Table 4: Chronological Evolution of The Variables Under Study

\begin{tabular}{llll}
\hline & $1990-1992$ & $1993-1996$ & $1997-1998$ \\
\hline Mean of Winner's Bid $(\$ / m)$ & 11.61 & 10.13 & 9.4 \\
Mean of Winner's Cost $(\$ / m)$ & 10.91 & 9.51 & 8.69 \\
Mean of Winner's Rent $(\$ / m)$ & 0.70 & 0.62 & 0.71 \\
Mean of Actual Number of Bidders & 7.72 & 6.43 & 9.44 \\
Variance of Costs & 0.87 & 0.68 & 0.54 \\
Mean of Size of Territory $(\mathrm{km})$ & 32.4 & 37.4 & 34.8 \\
Contracts $(\$ 25 \mathrm{~km})$ & $\$ 25 \mathrm{~km}$ & $>25 \mathrm{~km}$ & $>25 \mathrm{~km}$ \\
\hline
\end{tabular}

Table 5: City Cost Data Summary (Assuming Reserve Prices are Optimally Chosen)

\begin{tabular}{|l|l|l|l|l|}
\hline & Mean & $\begin{array}{l}\text { Standard } \\
\text { Deviation }\end{array}$ & Minimum & Maximum \\
\hline $\begin{array}{l}\text { Cost to the City } \\
\text { minus } \\
\text { Cost to the Suppliers }\end{array}$ & 0.144 & 0.065 & 0.057 & 0.485 \\
\begin{tabular}{|l|l|l|l|l|}
\hline $\begin{array}{l}\text { Cost to the City } \\
\text { minus } \\
\text { Reserve Price }\end{array}$ & 0.005 & 0.001 & 0.002 & 0.008 \\
\hline
\end{tabular}
\end{tabular}

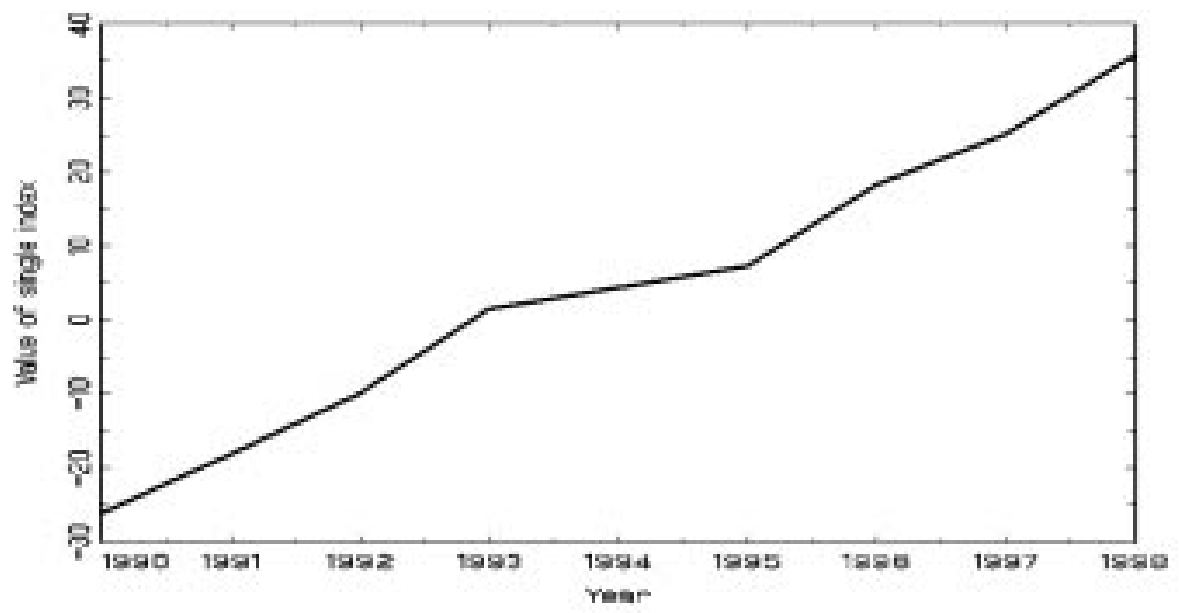

Figure 1: Single Index 


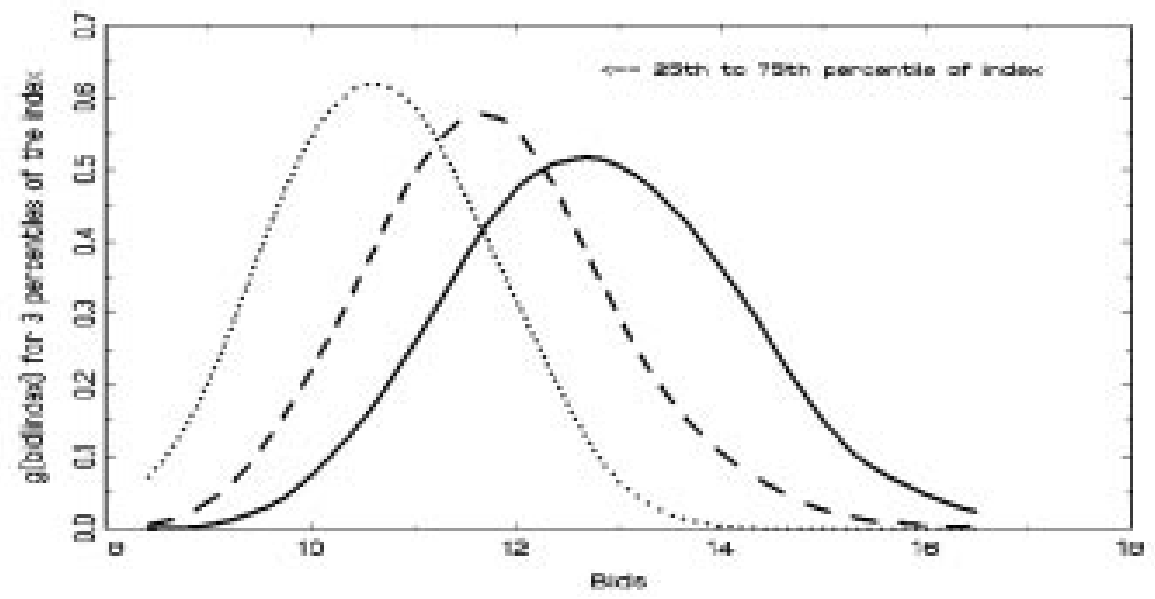

Figure 2: Densities of Bids for the 25th, 50th and 75th percentile

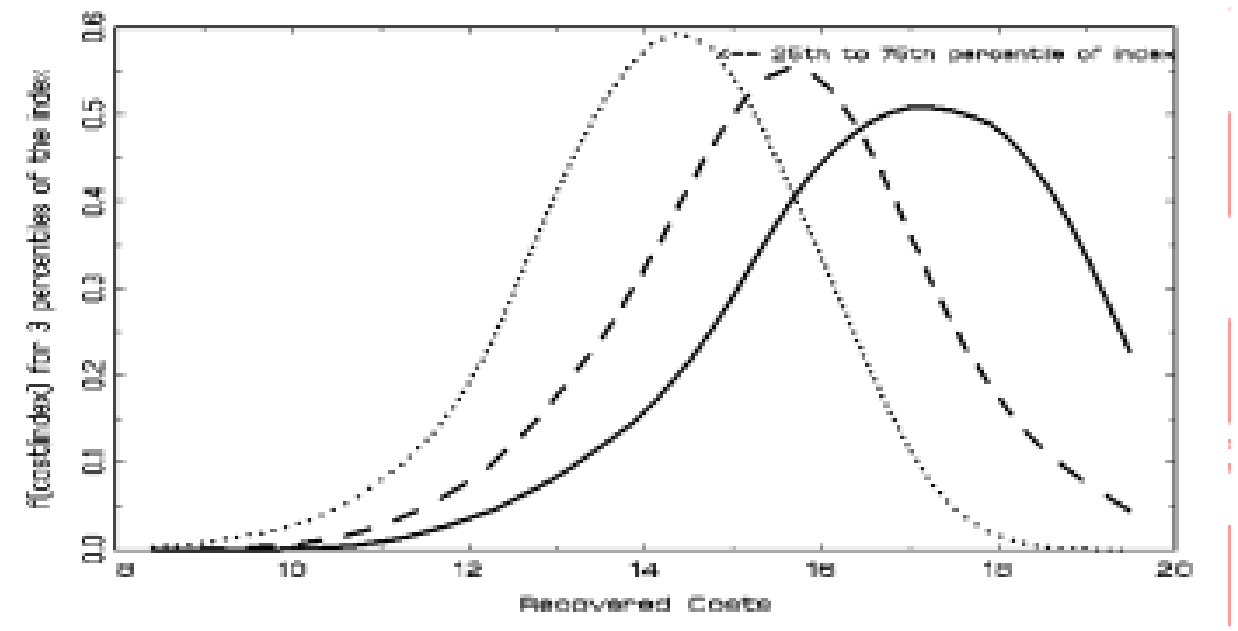

Figure 3: Densities of Costs for the 25th, 50th and 75th percentile 


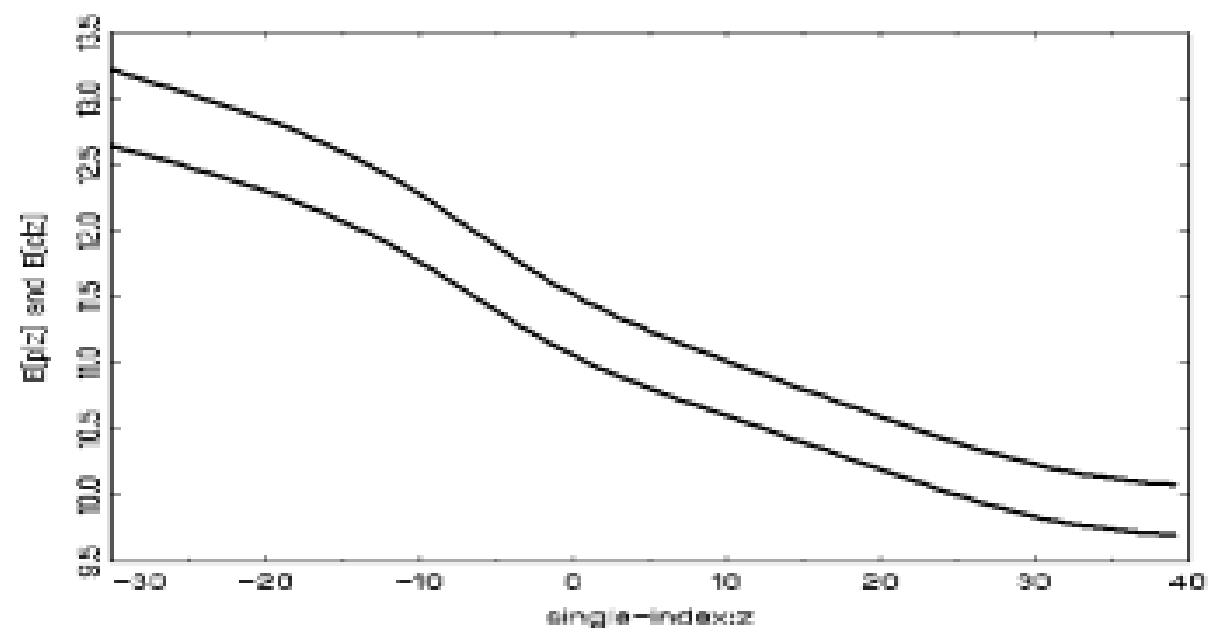

Figure 4: Conditional Expected Bids and Costs with Respect to Z

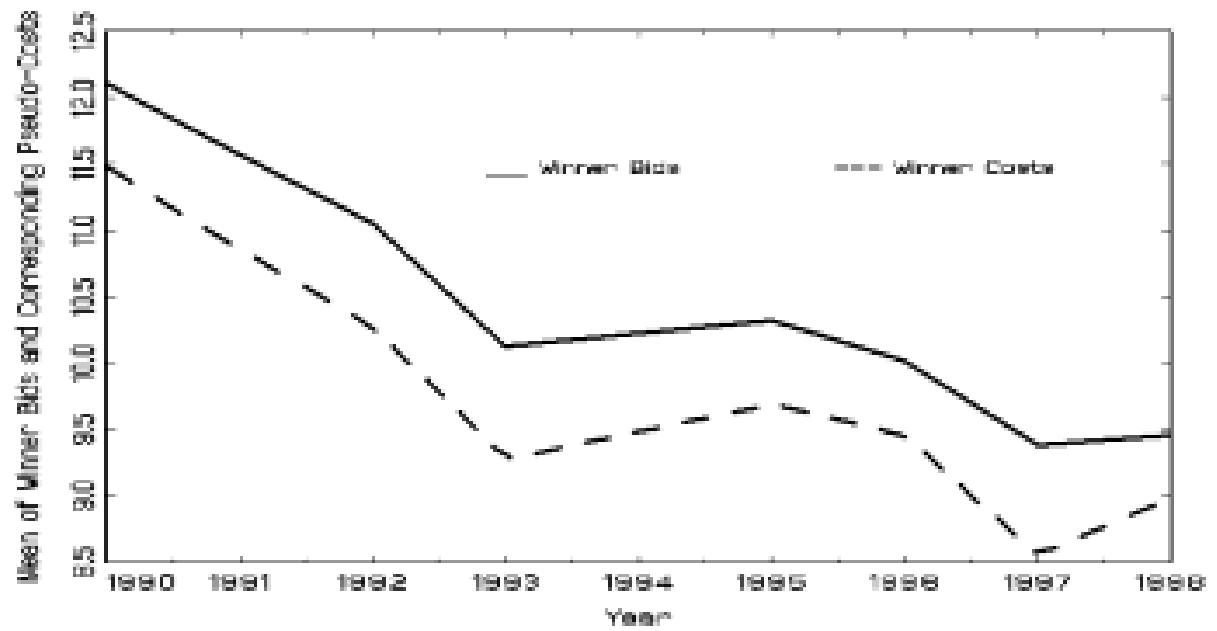

Figure 5: Mean of Winner Bids and Pseudo-Costs 